\title{
Biofuels: the good, the bad, the ugly-and the unwise policy
}

\author{
Henrik Wenzel
}

Published online: 20 May 2009

(C) Springer-Verlag 2009

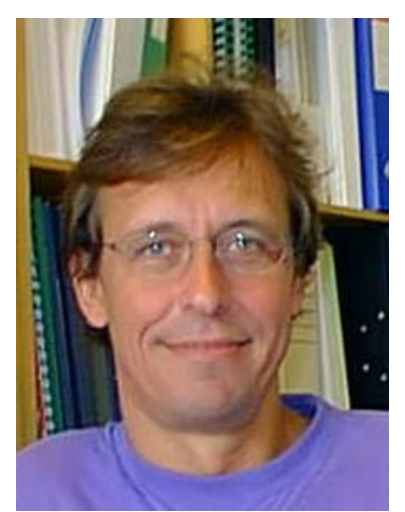

Throughout the world, nations are seeking ways to decrease $\mathrm{CO}_{2}$ emissions and to reduce their dependency on fossil fuels, especially oil, for environmental as well as geopolitical reasons. Being a renewable, $\mathrm{CO}_{2}$-reducing and easily storable energy carrier, biomass is a priority resource for fossil fuel substitution, and biomass is increasingly used for both the road transport and the heat and power sectors, with emerging interest in using it for aviation, sea transport and chemicals production as well. For the road transport sector, the conversion of biomass to the liquid biofuels of bio-diesel and bioethanol is at present a technological pathway promoted by governments in many countries.

\footnotetext{
H. Wenzel ( $\square)$

Faculty of Engineering, Institute of Chemical Engineering,

Biotechnology and Environmental Technology,

University of Southern Denmark, Campusvej 55,

5230 Odense, Denmark

e-mail: henrik.wenzel@kbm.sdu.dk
}

With the increasing interest in our biomass resource, however, the issue of competition for the biomass and the need for prioritising it has become evident. A review of scientific studies reporting on biomass potentials shows an interval from 75 to $400 \mathrm{EJ} / \mathrm{year}$ from the most pessimistic to the most optimistic estimates of the maximum biophysically available potential of biomass for energy purposes in 2030, being capable of around $10-50 \%$ fossil fuel substitution. This is what is judged to be biophysically available, and the studies including economic and market oriented considerations find the potential to be lower, i.e. in the interval of 75-150 EJ/year or 10-20\% fossil substitution. Further, studies looking at the biomass residue part only, i.e. the biomass potential not in competition with food production, the reported interval lies from 15 to $95 \mathrm{EJ} /$ year, or around $2-13 \%$ fossil substitution in 2030. My personal judgement is that we will never reach a level over $20 \%$ fossil substitution by biomass, be it residues or crops, and we will not reach such a level before energy consumption in general has risen more than that.

For several decades ahead, we still depend heavily on fossil fuels, and we can only replace them to the extent and at the speed that alternatives become available. As the magnitude of biomass that is or can be made available for energy purposes is small compared to the magnitude of the new potential customers for it, any long-term and largescale prioritisation of biomass for one purpose will imply a loss of alternative uses of the same biomass. If the lost alternatives are, then, significantly more efficient as well as economically more attractive in fossil fuels substitution and $\mathrm{CO}_{2}$ reduction, we lose more than we win. This is the case for most liquid biofuels, including first generation biodiesels (plant bio-diesels) as well as first and second generation bioethanol technologies used in Europe and the USA. When we prioritise biomass for these biofuels, we 
Fig. 1 The three main categories of system boundaries in existing biofuel studies. Full arrows designate induced flows, dotted arrows designate avoided flows

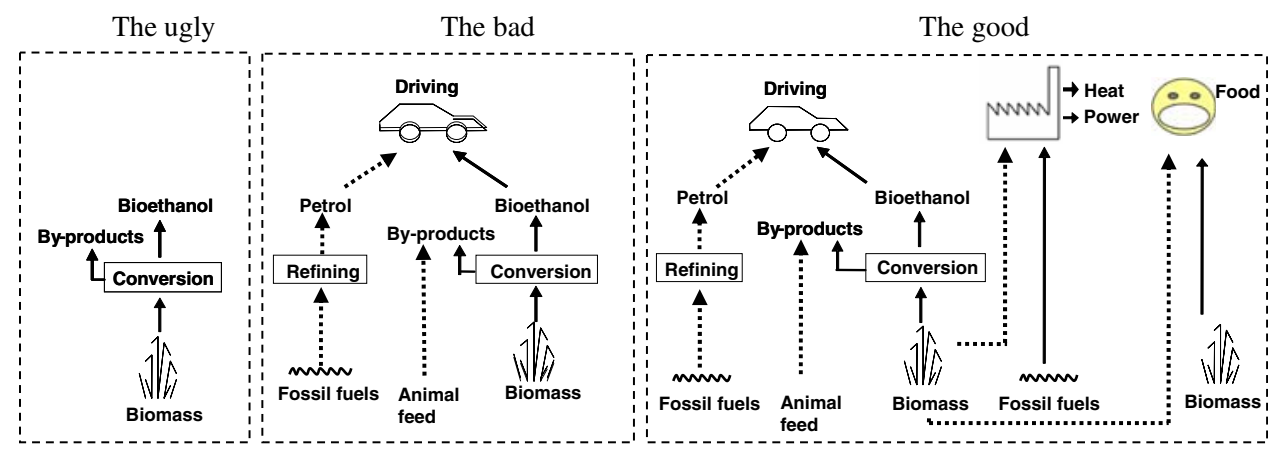

deprive ourselves the better alternative of using the same limited land and biomass for heat and power and running our cars on the fuels saved in the heat and/or power sectors.

If the United States of America would prioritise an efficient crop for wood pellet production, ship the wood pellets to Europe for oil substitution, ship the saved oil back, and run the cars on this oil, it would overall save more than twice the oil and twice the $\mathrm{CO}_{2}$ emission for less than onethird of the investment. In the EU, we use $40 \%$ of our oil outside the transport sector, most of which for heating purposes. We could take all the pellets, you could send us from your side of the Ocean, and we would welcome it. You might, of course want to use the pellets yourselves, in that case, you could consider where in the US to save oil or natural gas for heating or electricity by pellets and run your cars on what you save there. Compressed Natural Gas (CNG) is an excellent transport fuel, and countries like Germany and Sweden are establishing many CNG fuelling stations at present. Pellets for oil or pellets for gas in heat or power sectors combined with gas for oil in transport would give you twice the saving and much smaller investment per area of arable land or per ton of biomass than any known liquid biofuel technology, be it first or second generation. Let the farmers grow crops for pellets, let families with natural gas boilers in their house install a pellet boiler instead, and let them buy an energy efficient (European) $\mathrm{CNG}$ car to run on the saved gas, and the USA will have an energy policy tremendously more fuel efficient, $\mathrm{CO}_{2}$ efficient and cost-efficient than the present biofuel policy.

I thought the USA was a nation believing in the free market economy-but, in which, free market economy would anyone want to exchange a ton of biomass for 1 unit of oil for a certain investment, if one could get twice the amount of oil for a third of the investment on another exchange? Only mandatory blending and other market ignorant incentives can create such a mistake.

\section{The good, the bad and the ugly}

But why do so many studies then praise the environmental and resource saving aspects of liquid biofuels? And why do other studies arrive at different conclusions? Well, a closer look at the causes behind the differences in studies and conclusions reveals that the apparent large variations can be boiled down to simple differences in how the system boundaries of the studies are set. The studies fall into three main categories, which could be named: the good, the bad and the ugly; see the illustration (Fig. 1).

The category named 'ugly' comprises studies that look at the biofuel in isolation. They look at a narrow energy balance comparing the calorific value of total fossil fuels used to produce the biofuel to the calorific value of the biofuel itself. Some studies also comprise the co-product produced along with the fuel. They comprise studies on first generation biofuels, typically on bioethanol, and include the system producing the bioethanol including the growing of the crop and conversion into ethanol. They find the calorific value of the consumed fossil fuels to be just as high or even higher than the calorific value of the ethanol itself and argue against the use of bioethanol on these grounds.

The category named 'bad' comprises studies that look at transport in isolation. As opposed to the ugly category, they do acknowledge the fact that petrol and animal feed are displaced including their whole supply chain. They find that in the overall picture, more fossil fuels are, then, displaced than used. Looking at transport in isolation, this system boundary, however, does not respect the issue of competition between alternative customers for the same limited resource - the biomass and land.

The 'good' studies are the ones that look at transport in correlation with other biomass consumers in society, including food (first generation biofuels) as well as heat and power production (second generation biofuels). These studies unambiguously show that more is lost than gained when prioritising biomass and cropland for transport biofuels at the expense of heat and power. Looking at both $\mathrm{CO}_{2}$ reduction and fossil fuel savings, the conversion of biomass to heat and power or its use in chemistry can imply from fifty up to several hundred percent higher savings per ton of biomass and/or per hectare than biofuels, depending on the type of biofuel.

But what about the longer term-when we cannot exchange biomass for oil or gas in the heat and power 
sectors? Well first, at that time we will have an aviation sector and a chemical sector, which both are higher priority customers for carbon, based fuels and feedstock than road transport, and which together in 2030 are estimated to take over $100 \mathrm{EJ} / \mathrm{year}$ of biomass, i.e. more than the available non-food biomass. And, further, we will have an electric car with an energy efficiency of over $90 \%$-compared to today's world average efficiency of the combustion engine car of around 15\% - and allowing for wind and solar electricity buffering.

It is only a matter of time before we realise how unwise the world's present policies on biofuels are. But how do we pull out, when we do? 